\title{
NOTE ON THE THERMOELECTRIC PROPERTIES OF TANTALUM AND TUNGSTEN.
}

\author{
By W. W. Coblentz.
}

Tantalum is obtainable in fine wires; it is pliable and does not oxidize readily at ordinary temperatures, and hence suggests itself as a substitute for iron (steel) in connection with constantan wire in thermopiles. The following observations on the thermoelectric behavior of tungsten and tantalum may be of interest. The tantalum wire employed was $25 \mathrm{~cm}$ long and $0.048 \mathrm{~mm}$ in diameter. It was taken from an unused incandescent lamp. The resistance was $0.85 \mathrm{ohm}$ per $\mathrm{cm}$, which was about 0.9 that of a sample of steel wire. The ends of the tantalum wire were wound tightly around copper wires, about o.I $\mathrm{mm}$ diameter, and then soldered. The copper wires were joined to a potentiometer, by means of a mercury reversing switch, and the comparisons made against a standard cell. Observations were also made on copper constantan and on iron constantan couples made of wires $0.05^{13}$ $\mathrm{mm}$ in diameter. The temperature was varied from $10^{\circ}$ to $100^{\circ}$, and an attempt was made to eliminate the lag of the mercury thermometer. Observations were also made at the temperature of liquid air and of solid carbon dioxide. The results are shown in Fig. $\mathrm{r}$, in which the black dots indicate the observations on the tantalum-copper couple drawn to scale. ${ }^{1}$ The observations at $10^{\circ}$, $24^{\circ}, 32^{\circ}$, and $47^{\circ}$, respectively, belong to the first series. The observations at $17^{\circ}, 50^{\circ}$, and higher temperatures were made on a new couple and show no marked variation from the preceding. The circles show the observations on the constantan-copper couple, the ordinates (microvolts) being drawn to one-tenth the scale of the tantalum couple.

\footnotetext{
${ }^{1}$ The thermoelectric power of a tantalum-copper couple found by Pearson (Electrician 63 , p. 594, 1909) is only about one-tenth this value. Since no check measurements were made on known elements the discrepancy may be due to an error in recording the results. His observations were made by joining the couple with a galvanometer.
} 


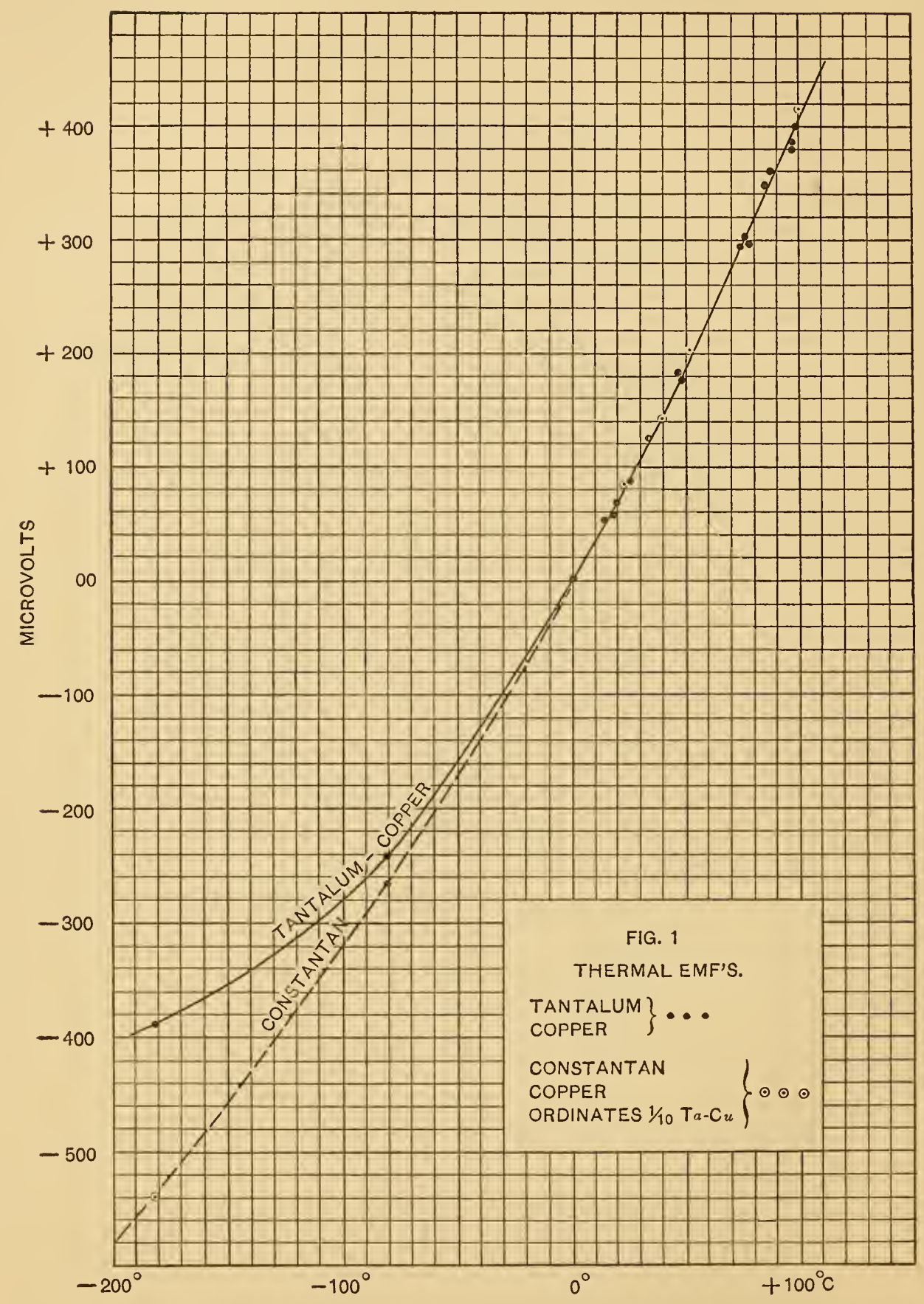


The results show that throughout the range investigated the thermoelectric power of tantalum (against copper) is about 4.I microvolts per degree, which is one-tenth that of the copper-constantan couple. The direction of the current is the same as in the copper-constantan couple.

The tungsten wire used in the present experiments was taken from a large "series" lamp. It was about I I cm long and 0.26 $\mathrm{mm}$ diameter. To the ends were wound copper wires O.I $\mathrm{mm}$ diameter and covered with solder. Tungsten is very brittle, and the sample was accidentally broken before the observations were completed, so that the observations at $23 \mathrm{I}^{\circ}$ and $269^{\circ}$ (the freezing points of tin and bismuth, respectively) were made with a length of wire less than $6 \mathrm{~cm}$ long, the copper wires being fused to the tungsten. It was found that this did not affect the results.

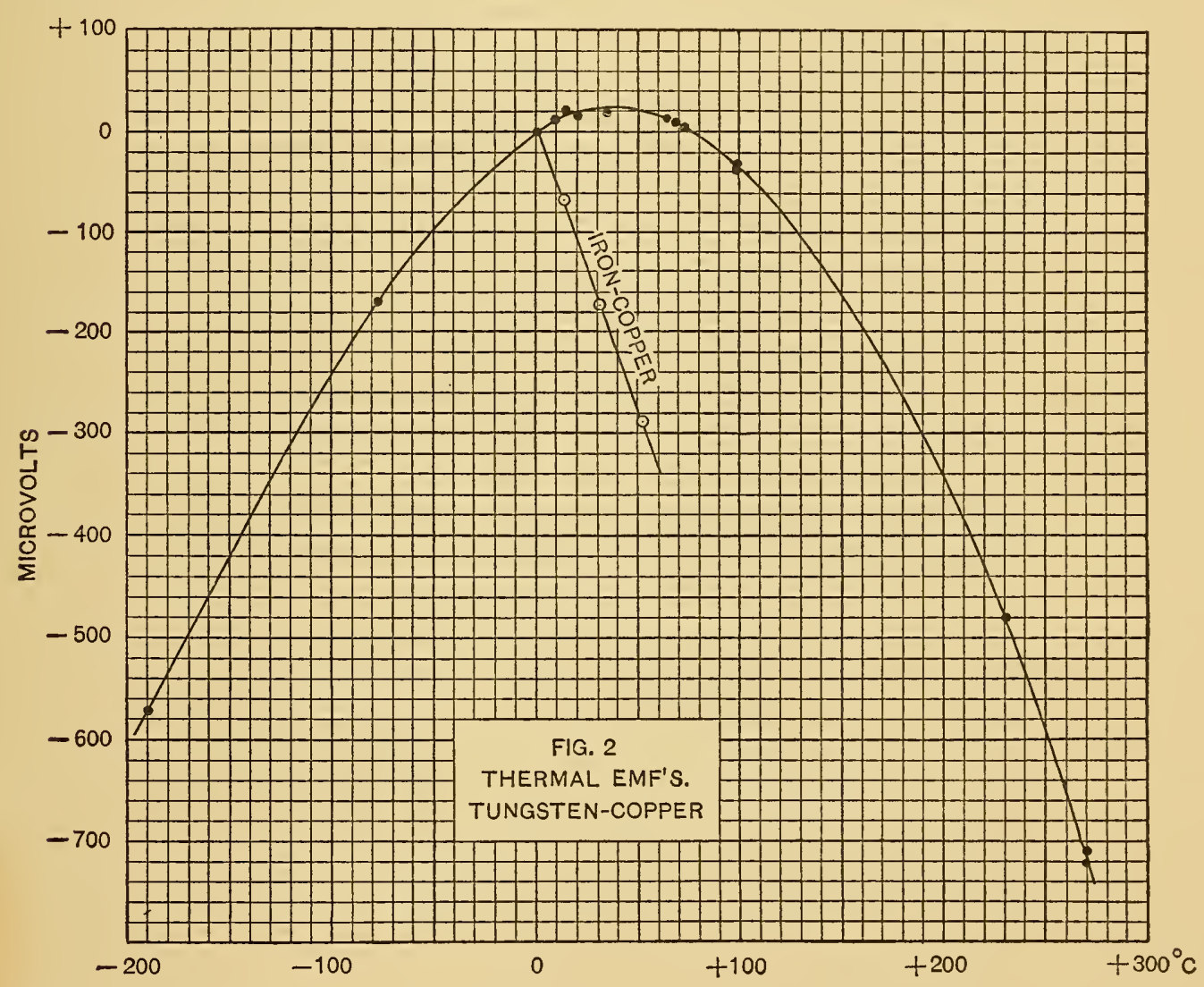

The thermal electromotive force curve of tungsten is given in Fig. 2, and is rather unusual in that its inversion temperature occurs at about $40^{\circ} \mathrm{C}$. Other combinations, which have an inversion $2192-$ No. $1 \longrightarrow 09-8$ 
temperature near $0^{\circ}$, are cadmium-iron at $170^{\circ}$ and copper-zinc at about $30^{\circ} \mathrm{C}$. From its appearance it is inferred that the thermoelectric curve is not a true parabola, as was also observed by Dewar and Fleming ${ }^{2}$ on numerous other metals. For temperatures below $-100^{\circ} \mathrm{C}$ the thermoelectric power (against copper) is about 3.5 to 4 microvolts per degree, while above $+200^{\circ} \mathrm{C}$ the thermoelectric power is about 4.5 microvolts per degree, so that tungsten, like tantalum, shows no apparent advantage in thermoelectric work.

WASHINGTON, January I 5, I909.

${ }^{2}$ Dewar and Fleming, Phil. Mag. 40, p. 95, I 895. 